\title{
Learning Approaches for Entrepreneurship Education
}

\author{
Ileana Hamburg \\ Institut Arbeit und Technik, WH Gelsenkirchen, Germany
}

\begin{abstract}
ABSTARCT
Entrepreneurship education is one important topic for all European countries preparing people who can contributes to the ability of an economy to innovate, to create new businesses and new ideas. In both higher education as well as in vocational education and training (VET), suitable learning methods, special education modules oriented to entrepreneurial competences including traversal skills and attitudes as well as more specialized knowledge and business skills are necessary and could be supported by mentors. More options and opportunities for European and international exchanges are necessary. This paper will give information about entrepreneurship education, mentoring and suitable learning methods for entrepreneurs, particularly problem based learning - PBL, conclusions and recommendations.
\end{abstract}

Keywords: entrepreneurship education, diversity, mentoring, problem based learning

\section{INTRODUCTION}

Entrepreneurship education has a role in supporting students to achieve the knowledge and skills to act in an entrepreneurial way (Aarchus Technical College, 2013). This has the potential to raise the awareness of self-employment as a possible career option for young people.

The importance of entrepreneurship education is also highlighted in the European 2020 strategy for New Skills and New Jobs.

Mentoring is a special form of active support for entrepreneurship competence, a "natural support". It can also help young people with special needs to believe in themselves and boost their confidence. Mentoring assists this by developing entrepreneurial skills in a practical manner.

In both higher education as well as in vocational education and training (VET), special education modules oriented to entrepreneurial competences including transversal skills and attitudes as well as more specialized knowledge and business skills could be supported by mentors.

In Europe, due to the expanding of wealth and growth into new regions the need for a diverse approach to social and employment settings has become more and more essential.

In all European countries more options and opportunities for European and international exchanges are necessary.

Research results show that people learn more efficiently when they discuss the learning material with others. Problem based learning (PBL) is based on tutorial groups in which students work together on a specific problem and is suitable for entrepreneurial learning. 
This paper will give information about entrepreneurship education (part 1), Diversity and Mentoring (part 2) and suitable learning methods for entrepreneurs, particularly PBL (part 3 and 4), conclusions and recommendations (part 5).

\section{ENTREPRENEURSHIP EDUCATION}

Entrepreneur usually means an individual who organizes or operates businesses. The word "entrepreneurs" was first used by the Irish-French economist Richard Cantillon who defined them as "non-fixed income earners who pay known costs of production but earn uncertain incomes" (Tarascio, 1985). Howard Stevenson (Gartner \& Baker, 2010) writes "Entrepreneurship is the process by which individuals pursue opportunities without regard to the resources they currently control". Entrepreneurship is the art of being entrepreneur, so to be able to turn ideas into action. This implies creativity, innovation and risk taking, and the competence to plan and manage projects in order to achieve objectives (Stepherd, 2004; Hamburg, 2014).

Entrepreneurship education programs should offer students the tools to be creative, to solve problems efficiently, to analyse a business idea objectively, and to communicate, cooperate, lead, develop and evaluate projects. Students can learn to set up their own businesses if they can test their ideas in an educational, supportive environment.

But the benefits of entrepreneurship education are not limited to support start-ups, innovative ventures and new jobs. Entrepreneurship helps young people to be more creative and selfconfident in all their activities.

Education for entrepreneurship can be particularly effective in vocational education and training (VET) particularly in the initial stages, as students are close to entering working life and self-employment could be an option for them.

Entrepreneurship is included in the national curricula for vocational education in many European countries, but there are some gaps in these programs (European Commission, Enterprise and Industry, 2009):

- Teaching methods are ineffective,

- Entrepreneurship is not included in all parts of the VET system,

- Student participation is limited,

- Teachers are not fully competent,

- Business people are not involved,

- The practical element is missing,

- Entrepreneurship is not linked to specific training subjects or professions.

- Education is not linked with labour market demands.

It is important that entrepreneurship education tries to address these gaps.

Mentoring within entrepreneurship education can address some of these as it brings in expertise from business, it is practical and can assist in linking the training to particular professions and labour market demands (O’Brien \& Hamburg, 2014).

In some countries special training for self-employment is fully integrated in all entrepreneurship courses. In other cases the objective of entrepreneurship education is broader, aiming rather to develop soft entrepreneurial skills and including training for selfemployment only in some specific fields. 
A partial lack of competence of teachers of entrepreneurship is perceived in many cases as a problem, i.e. regarding their practical experience of entrepreneurship, if not their theoretical knowledge. Improvement is greatly needed in this area. Most countries report that some training courses on entrepreneurship are offered to teachers, but few offer a systematic approach.

\section{Mentoring}

\section{RESEARCH ISSUES}

Mentoring is a human resource development approach and a vital aspect of knowledge management which needs to be looked by all organizations and education institutions wishing to improve their efficiency (Kram, 1985).

Educators and practitioners have noted the importance of mentorship in promoting leader development and career opportunities (Srivastava 2013).

Some literature on mentorship has been utilized by both psychologists and educators. This literature has focused predominantly on the impact of career mentoring in large companies and within higher education. According to Kram's mentor role theory (1985), mentors provide career development in order to advance within the organization, and psychosocial advancement, contributing to the mentee personal growth and professional development. The literature has found that receiving mentorship has been associated with positive career outcomes (Srivastava 2013).

Both functions of the mentoring, career advancement and professional development increase the mentees opportunities. Many of these methods can be used for mentoring in entrepreneurial education. For example, they use experienced entrepreneur-mentors to help their mentees to understand that a failed business is not the end of a career, but rather an important part of their entrepreneurial training. Mentorship from an entrepreneur can provide students with a greater level of security and inspiration. It can help students to know how a business was developed directly from its founder, and can be more effective than being mentored by an employee or an investor in this case. Also the story of an unsuccessful business venture is useful for students, particularly if it was a courageous idea, or the entrepreneur would like to create other interesting ventures.

Governments, industry, universities try to demonstrate how mentorship can increase economic impact and have created courses and programs which feature mentorship components. Fewer show the use of mentoring in entrepreneurial education in VETs.

In higher education peer mentoring is used frequently to retain students, it supports students where they feel isolated and consider leaving education. It is intended to expand this method also in vocational education (Hamburg, 2014).

For mentors supporting young entrepreneurs (19-25 years), it is important to focus on developing life plans and passion for a career, helping young mentees to keep their vision in sight and to reflect what is happening (Cull, 2006). Softer skills such as listening, communicating as well as more technical ones including the review of business plans and meeting objectives are necessary. Mentors should maintain mentees motivation, encouraging them to persist and implement their ideas.

Supporting students/starters in small and new business creates a contribution to the local community, more jobs and a more attractive place to do business. Mentors will gain a better 
understanding of challenges facing small business which could enhance their working life or their retirement period.

It is also important to involve the company's managers in a mentoring program to coach and provide feedback to employees who are different from them (Bozeman \& Feeney, 2007).

Many education institutions and companies offer diversity initiatives to encourage collaboration and understanding, but most diversity initiatives do not go far enough to promote real diversity and improve firm's competitiveness. Particularly within VET such initiatives are missing.

\section{Learning Methods}

Entrepreneurship Learning does not relate to a single occupation; it covers a variety of occupational skills and learners. Students engaged in entrepreneurship education should acquire different competences according to the focus of their learning (Aarchus Technical College 2013).

- entrepreneurial competence, knowledge and understanding in setting up a business/enterprise, as well as personal skills and attitudes that define an entrepreneur; enhanced entrepreneurial skills include:

- $\quad$ working with distributed (geographically) production or companies

- working in foreign languages

- professional and vocational competence key skills, knowledge and understanding like problem solving, working with others, ICT, and health \& safety. Also skills, knowledge and understanding that are related to different occupations and professions (e.g. finance, retail) and environmental issues

- communication and social competence key skills, knowledge and understanding in effective communication and interpersonal activities, as well as in ethical, moral, and cultural concerns

- personal competence development of autonomy, responsibility, personal role, own performance and learning

The implementation of entrepreneurship teaching and learning methods, particularly in schools and VET, requires structural changes in most countries. In many institutions of higher education and VET, where learning approaches are not driven by national policy, introduction of entrepreneurial teaching and learning depends on the institution which should also make a cultural change including diversity approaches.

Knowledge about diversity as well practical training should be offered in entrepreneurial education and these will be more efficient than large, abstract diversity lectures. The main objectives of such training include awareness, education and positive recognition of the differences among people in the workforce.

Besides a changed or open curriculum, teachers should be trained on entrepreneurial learning methods which focus on entrepreneurship education that fosters social inclusion.

There is a need to train teachers both during their initial training and in continuous development programs. Teacher training in entrepreneurship should include the use of ICT and placement methods in companies.

One important problem is to assess entrepreneurial skills, attitudes and knowledge of students. The role of assessment is to foster learner confidence. Evaluation and monitoring 
should be built into projects, with qualitative and quantitative metrics to understand impact and effectiveness. Relevant policies/strategies should be assessed regularly, and have a feedback loop that will ensure that relevant adjustments/improvements take place.

In the report of the Expert Group (European Commission, 2013) some identified good practices are presented in order to improve entrepreneurial education:

- There is a good balance between theory and practice: the programme or activity is action oriented, based on experience and project work. It aims to improve the students' abilities to work in a team, develop and use networks, solve problems, and spot opportunities.

- Students are actively involved in the learning process, and responsible for their own education.

- Students are exposed to real-life work situations and encouraged to take part in extracurricular activities. External events, activities and contests are organized.

- Teachers have an appropriate qualification in entrepreneurship (through experience in business and/or participation in training). They use up-to-date study materials and upto date knowledge.

- The programme or activity is part of a wider scheme: students are followed after participation in the programme, and are referred to the right support mechanisms if they want to start up a business.

In the following we describe shortly Problem Based Learning (PBL) as a suitable form for Entrepreneurial education.

\section{Problem Based Learning}

Problem Based Learning (PBL) has been proven to develop higher order thinking and critical thinking skills. There are many different approaches to PBL (Barrow, 1986; Jonassen, 1997; Hemlo, 1998), however little research has been done into the most effective methods in terms of learner success (Huag, 2011). In addition PBL has yet to be adopted outside academic contexts. PBL would be an excellent method of training for SMEs. It allows the learner to develop skills relevant to the needs of the company, it is conducted in a work based environment, it provides them with the skills to sustain the company beyond the initial training, it is low cost and it directly solves problems for the SME providing an immediate return. (Bell, 2010; Walters \& Sirotak, 2011).

Donnelly (2010) highlighted that little is known about the use of technology in PBL. However after conducting a study in an academic context of the use of Communities of Practice (CoPs) (Wenger, 1998; Hamburg \& O`Brien, 2014) for PBL he found that CoPs provide an opportunity to enhance collaboration and extend face to face time with mentors and peers. In a business environment PBL, by using mentoring, CoPs and social media can be used to provide an opportunity for the communication between the mentor and mentee and to work with peers (or experts inside and outside the company) to find potential solutions to the problem or approaches to solve the problem.

PBL is suitable for entrepreneurship education, i.e. by presenting properly real problems like "starting a business". It creates motivation and working energy in the students.

It is important to have a structured way in using PBL, because at the beginning the students feel they know nothing but after a short introduction and the guidance from the trainer/teacher they realise that they themselves can be the drivers in creating their own business. 
PBL is typically organized in small groups of learners, accompanied by a trainer, teacher, facilitator. During this process, a series of problems are presented to learners with guidance early in the PBL process; then guidance could be less as learners gain expertise, feel more confident with the subject matter and become more competent with the procedures.

It is better to begin with examples of solved problems and later, introduce students in more complex problems. Then adding components to make them more realistic should follow. It is important to begin with simplified versions of real world problems to progressively add components, because this motivates learners as they slowly gain expertise and take ownership.

During the PBL process learners should discuss the problems, define what they know, generate hypotheses, derive learning goals and organize further work. Results may subsequently be presented to larger groups (under guidance from an instructor). A PBL cycle should conclude with learners reflecting on the learning that has taken place. In the following we present steps which could be used by teaching PBL. There is an adaptation of existing ones (www.umpblprep.nl/pbl-step-by-step)

\section{a) Clarifying the task}

The purpose of the first step is to explain the task, to agree on the meaning of the various words and terms and on the situation described in the problem:

- Reading through the task and claryfing the methodology

- Identifying and explaining all difficult words in a group so that everyone understands what the task is about

- Choosing the problem to be solved if there are more options

\section{b) Defining the problem}

Definition of the problem is the main goal during this phase, that means:

- Precise definition of the problem

- The group agrees on which aspects need to be explained or resolved

- Making a list of all questions involved to the task, which are needed to be answered

\section{c) Brainstorming}

This should result in ideas to structure the problem. Each individual may express his or her ideas free and without immediate discussion. The tasks could be the followings:

- Brainstorming existing solutions for similar problems

- Analysis of questions

- Everyone can provide input on the various questions while thinking out loud

- The aim is not to immediately evaluate the ideas and input of the group members, all ideas and pieces of information are welcome - good or bad, right or wrong

\section{d) Analysing the possible solutions}

- Review steps 2 and 3 and arrange explanations into tentative solutions.

- Making an overview of all solutions provided

- Everyone has the opportunity to express an opinion on the solutions

- Making clear what is not understood, on which aspects the group members have their doubts and which areas are having conflicts in opinion

- Arrange explanations into tentative solutions assessing the solutions. 


\section{e) Formulating learning objectives}

- Learning objectives are formulated for all the problems which the group has not succeeded in solving or about which the group has insufficient information

\section{f) Self-study}

- With the help of the learning objectives, the group members start working on their own in order to work out the learning objectives

- The material found by researching will be collected by each member

- Optionally the collected material can be uploaded to a data pool or be sent to a group leader

Some tips to select study material efficiently:

$>$ Don't just look in a book in a particular section, but also use your literature folder.

$>$ Take an active attitude when studying: While reading, check whether your insight into the issues involved is improving.

$>$ Try to put the material into your own words: Ask yourself, "How would I explain this to someone else?"

$>$ Take clear notes of the most important points.

$>$ Read up on background information regarding the learning objectives. It's not enough to look only for information needed to answer the learning objectives - you also need more background information.

\section{g) Working a final solution}

- Discussing the answers found regarding the learning objectives

- Validating all information found and evaluating the own work

- Working out a synthesis for the problem

\section{PROJECTS}

The EU Erasmus+ project, supporting PBL in entrepreneurial education and in small and medium sized enterprises (SMEs) through ICT facilitated mentoring - Archimedes - will develop a framework for organisational problem-based learning and supports the use of this form of learning. It is expected that these approaches will be widely adopted in entrepreneurial education and SMEs.

The main project objectives are:

- Collecting best practices in PBL and other forms of learning used by SMEs

- Development of an organizational PBL framework with effective support mechanisms such as mentoring and ICT based social networking

- Creation of a curriculum and training modules to train mentors

- Creation of a curriculum and training for entrepreneurial learning to be used in VET and for staff in SMEs in PBL blended with other learning forms

- Accreditation of the training course and recognition of such forms of learning in three higher education institutes in Europe

PBL will be supported by an ICT platform taking into consideration the PBL steps described below. 
PBL Process

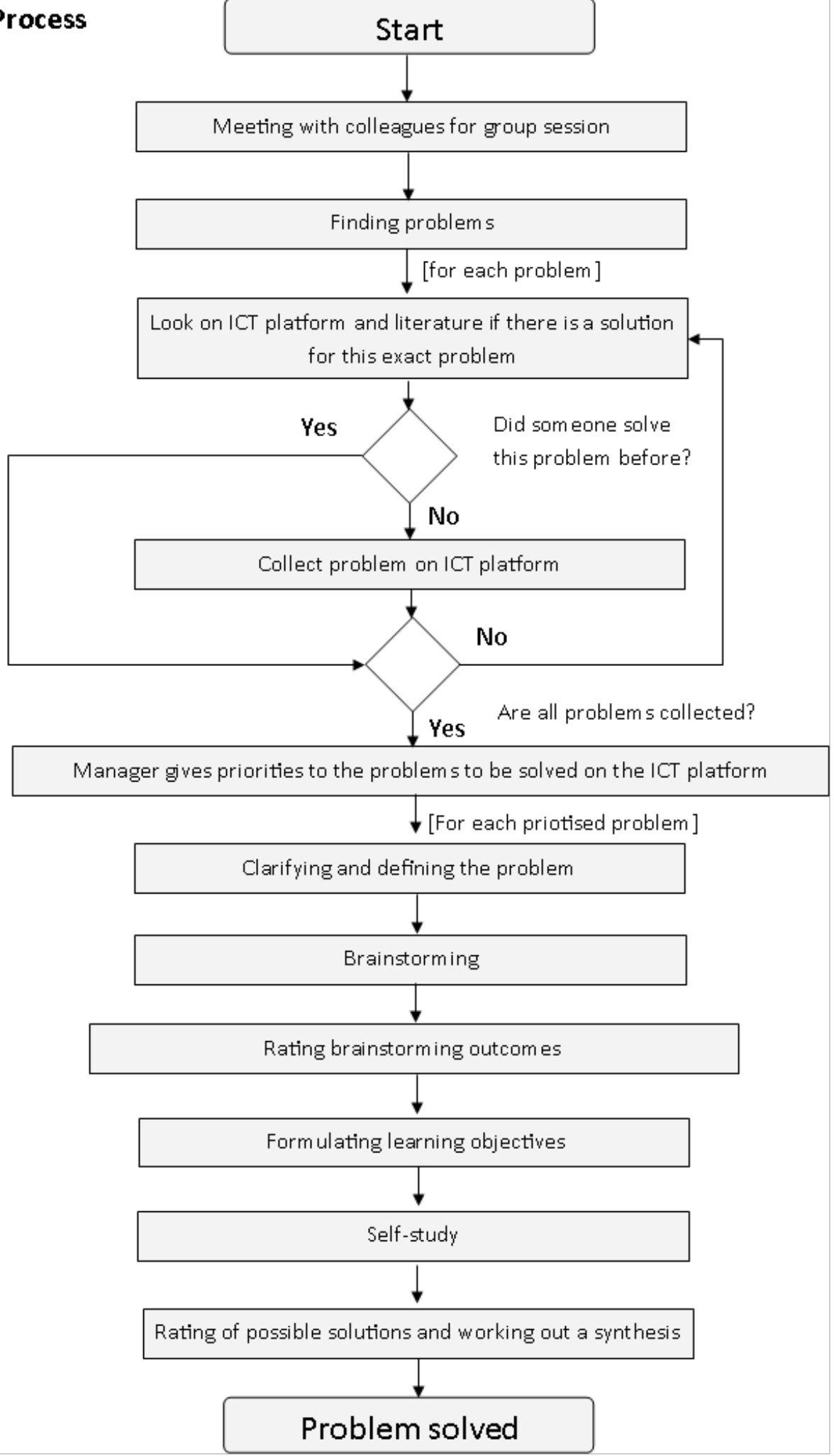

Figure 1: Flow chart of a PBL supporting ICT platform (source IAT)

The main objective of the on-going European projects ENTER (to) entrepreneurship is to support the achieving of entrepreneurial competences and opening minds of young people for innovation and learning by showing them advantages in both professional and everyday life and helping them by mentoring and new technologies. This Project answers to problems concerning changing labour market and unsufficient preparation to new situations by young people as well as lack of entrepreneurial education in formal systems. Growing SME's role in 
every European country causes necessity of creating new, more entrepreneurial attitudes. People, who don't recognize those attitudes can't find their place on labour market. That causes low motivation, self-confidence and sometimes social exclusion. Some activities of the project:

- To implement four seminars and international cooperation to prepare policy for local communities

- To develop a guide book for Community Entrepreneurial Strategic Development

- To organize entrepreneurial attitude training

- To organize motivation workshops, where participants can get aware of their potential, skills and creativity

- To organize advanced training steps to achieve business, technical, financing, selling skills.

- To provide support for start up's and potential entrepreneurs

- To exchange experience within networking meetings and conferences organised between partners to transfer valuable tips for new entrepreneurs and exchange visions and contact among start up's.

\section{DISCUSSION AND CONCLUSION}

Development of entrepreneurial attitudes should become one goal of education and require cooperation of all actors involved. A clear signal that entrepreneurship is important for all students could be done by introducing it as an explicit goal in the curriculum. This is a help for teachers who would like to participate with their students in entrepreneurial activities.

The effects of different types of mentorship in entrepreneurship education are still poorly theorized and empirically not well understood. Mentorship can address issues concerning entrepreneurial education such as integrating business people and practical expertise into the programs, however research needs to be conducted into how to exploit mentoring fully within these programs and to evaluate the effect of mentorship on the learning outcomes of the student.

Implementation of PBL requires some changes in the curriculum of entrepreneurship education and trainers/teachers with special knowledge. Rooms should be available for group discussions and the libraries should contain references which allow students to research for their PBL cases.

\section{ACKNOWLEDGMENTS}

This paper describes work within the on-going European projects Archimedes and ENTER.

\section{REFERENCES}

Aarchus Technical College (2013). Standards for Qualifications in Entrepreneurship Learning. An EU-funded project managed by the European Agency for Reconstruction http://www.masht-gov.net/advCms/

Documents/Standards_for_Qualifications_in_Entrepreneurship_Learning.pdf

Barrows, H.S. (1986). A taxonomy of problem-based learning methods. Medical Education 20, 481-486.

Bell, S. (2010). Project-Based Learning for the 21st Century: Skills for the Future, The Clearing House: A Journal of Educational Strategies, Issues and Ideas, 83:2, 39-43.

Cull, J. (2006). Mentoring Young Entrepreneurs: What Leads to Success? International Journal of Evidence Based Coaching and Mentoring, 4(2), 8-18.

Donnelly, R. (2006). Blended problem-based learning for teacher education: Lessons learnt learning. Media and Technology, 31(2), 93-116. 
Education and Culture DG (2013). The Future of Learning and Curriculum development - Draft Thematic Report http://ec.europa.eu/education/policy/strategic-framework/archive/documents/future-of-learning_en.pdf

European Comission. Entreprise and Industry (2009). Entrepreneurship in Vocational. Education and. Training. Final report of the Expert Group. ec.europa.eu/.../sme/.../vocational/entr_voca_en.pdf

Gartner, W.B. and Baker, T. (2010). A plausible history and exploration of Stevenson's definition of entrepreneurship", Frontiers of Entrepreneurship Research, 30(4), 2.

Hamburg, I. (2014). Improving young entrepreneurship education and knowledge management in SMEs by mentors. In: World journal of education 4, no. 5, 51-57.

Hamburg, I. and O'Brien, E. (2014). Engaging SMEs in cooperation and new forms of learning. In: Computer and information science 7 , no. $1,9$.

Hamburg, I. and O'Brien, E. (2014). Using strategic learning for achieving growth in SMEs. Journal of information technology and application in education, 3(2), 77-83.

Hmelo, C.E. (1998). Problem-based learning: Effects on the early acquisition of cognitive skill in medicine. The Journal of the Learning Sciences, 7(2), 173-208.

Huag, W. (2011). Theory to reality: a few issues in implementing problem-based learning, Education Tech Research Dev., vol. 59.

Johnson, W.B. and Anderson, G.R. (2010). Formal Mentoring in the US Military. Naval War College. Rev. 63(2).

Jonassen, D.H. (1997). Instructional design models far well-structured and ill-structured problem solving learning outcomes. Educational Technology Research and Development, 45(1), 65-94.

Kram, K. (1985). Mentoring at work. Developmental relationships in organizational life. Scott, Foresman \& Company, Glenview, ISBN 0-673-15617-6.

O'Brien, E. and Hamburg, I. (2014). Supporting sustainable strategies for SMEs through training, cooperation and mentoring. Higher education studies 2014, 4(2), 61-69.

PBL step by step | UM PBL PREP www.umpblprep.nl/pbl-step-by-ste

Shepherd, D.A. (2004). Educating entrepreneurship students about emotion and learning from failure. Academy of Management Learning \& Education, 3(3), 274-287.

Srivastava, S.B. (2013). "Network Intervention: A Field Experiment to Assess the Effects of Formal Mentoring on Workplace Networks". University of California, Berkeley, Working Paper.

Tarascio, V.J. (1985). Cantillon's Essai: A Current Perspective" Journal of Libertarian Studies, 7 (2), $249-257$.

Walters, R. and Sirotiak, T. (2011). Assessing the effect of project based learning on leadership abilities and communication skills. The 47th ASC Annual International Conference Proceedings.

Wenger, E. (1998). “Communities of Practice: Learning, Meaning and Identity”. Cambridge MA: Cambridge University Press. 